encouraged to breast feed for at least three months their babies would benefit and suggest that maternity leave allowances should reflect this. Our data suggest that a minimum of 12 weeks should be allowed after delivery and probably more. In addition, there is also a strong case for the provision of creche facilities at work to allow nursing mothers to continue breast feeding. The present arrangement puts pressure on mothers who have to return to work either to choose bottle feeding from the start or to discontinue breast feeding prematurely.

The American Academy of Pediatrics reported that despite methodological imperfections most studies have found a protective effect of breast feeding against gastrointestinal infection and none have found an adverse effect. ${ }^{16}$ Studies with methodological flaws may suggest spurious advantages of breast feeding but may also obscure true benefits due to negative biases. Our study, which attempted to meet basic methodological requirements, strongly suggests that breast feeding still has an important part to play in preventing infection among infants in developed countries.

This work was funded by a grant from the Scottish Home and Health Department; the help of the Dundee health visitors is gratefully acknowledged.
Plank SJ, Milanesi ML. Infant feeding and infant mortality in rural (Chile. Bull WH( ) 1973;48:203-10

2 Habicht J.P. Davanzo J, But\% WP. Does breastfeceding really save lives, or are apparent benefits due to biases? Am f Epidemol 1986:123:279-90.

Bauchner H. Leventhal JMI. Shapiro ED. Studies of breastfeeding and intections. How good is the evidence? F.A.MA 1986;256:887-92.

intections. How good is the evidence? FA.MA 1986;256:887-92.
+ Cunningham AS. Breast feeding is protective. Pediatrics 1987;79:1052-3.

4 Cunningham AS. Breast feeding is protective. Pedatrics 1987;79:1052-3.
5 Cunningham AS. Morbidity in breastfed and artificially fed infants. II. Cunningham AS. Morbidity
7 Pediatr 1979;95:685-9.

6 Chandra RK. Prospective studies of the effect of breastfeeding on incidence of infection and allergy. Acta Paediatr Scand 1979;68:691-4.

7 Fergusson DM, Horwood JL, Shannon FT, Taylor B. Breastfeeding, gastrointestinal and lower respiratory illness in the first two years. Aus P'aediatr 7 1981:17:191-5.

8 Baker RJ, Nelder JA. The GLIII1 svstem. Release 3777. Oxford: Numerical Algorithms Group, 1985.

9 Taylor B, Golding J, Wadsworth J, et al. Breast-feeding, bronchitis and admissions for lower-respiratory illness and gastroenteritis during the first five vears. Lancet 1982;i:1227-9

10 Welsh JK. Mav JT. Anti-infective properties of breast milk. I Pediatr 1979;94:1-9.

11 Cunningham AS. Breast feeding and health. 7 Pediutr 1987:110:658-9.

12 Matta LJ, W Watt RG. Host resistance to infection. Am f C.lin Nutr 1971:24:976-86.

13 Theodore CM, Losonsky G, Peri B, Fishout M. Rothberg RM, Ogra PI Immunological aspects of colostrum and milk; development of antibod response to respiratory syncytial virus and serum albumin in the human and rabbit mammary gland. In: Strober W, Hanson LA, Sell K, eds. Recen adrances in mucosal immunity. New York: Raven Press, 1982:393-403.

14 Martin J, White A. Infont feeding 1985. London: Office of Population Censuses and Survers/HMSO, 1988

15 Department of Health and Social Security. Present dav practice in infant feeding. London: HMSO, 1988. (Report on Health and Social Subjects No 32.

16 Kovar MG, Serdula MK, Marks JS, Fraser DW. Review of the epidemiolog ic evidence for an association between infant feeding and infant health Pediatrics 1984;74:615-38.

(Accepted 30 October 1989)

\title{
Monitoring of blood glucose concentration in subjects with hypoglycaemic symptoms during everyday life
}

\author{
O Snorgaard, C Binder
}

\begin{abstract}
Objective-To study the persistence of hypoglycaemic symptoms, changes in blood glucose concentrations, and the relation between reported symptoms and measured blood glucose values in functional hypoglycaemia.
\end{abstract}

Design-Re-evaluation of symptoms in patients admitted consecutively with suspected hypoglycaemia followed by a case-control study.

Setting-The Steno Memorial Hospital in Gentofte, Denmark, which specialises in the diagnosis and treatment of and research on endocrine disorders, including hypoglycaemia.

Patients-21 Subjects admitted consecutively with hypoglycaemic symptoms that were relieved by eating in whom insulinoma and other organic disorders presenting with hypoglycaemia had been ruled out. Twelve of these subjects with persistent symptoms entered the case-control study, as did a matched control group.

Interventions-Four days of monitoring blood glucose concentrations at home, six daily samples being taken in fixed relation to meals by the finger prick method. Extra samples were taken when symptoms occurred.

Main outcome measures-Blood glucose concen-

Steno Memorial Hospital, DK-2820 Gentofte,

Denmark

O Snorgaard, MD, research

fellow

C Binder, MD, chief physician

Correspondence to:

Dr Snorgaard.

BrMed F 1990;300:16-8 values, and glycated haemoglobin concentration were not significantly different in all patients compared with the control subjects and in patients with symptoms during the study compared with controls.

Conclusion-Hypoglycaemic symptoms during everyday life in apparently healthy subjects are persistent but are not related to chemical hypoglycaemia.

\section{Introduction}

Denmark, unlike Britain, has not been spared the epidemic of functional hypoglycaemia seen in the United States during the past two decades. ' 2 We share the widespread scepticism about whether functional hypoglycaemia is a disease..$^{3+}$

Subjects complaining of hypoglycaemic symptoms during their everyday life that disappear after eating are regularly evaluated in our clinic by means of a fast of one to three days. If test results are negative hypoglycaemia is not recognised. On an empirical basis, however, a diet low in refined sugars and rich in fibre is recommended. The five hour oral glucose tolerance test has, in our opinion, no diagnostic value in these subjects. ${ }^{6.9}$

The uniformity of the symptoms at presentation in different countries ${ }^{6}$ and the general recognition of "postprandial" or "reactive" hypoglycaemia as a possible diagnosis by European diabetologists, ${ }^{10}$ however, made us study the persistence of hypoglycaemic symptoms in a group of patients with functional hypoglycaemia. In addition, we tested whether chemical hypoglycaemia could be shown during everyday life and in relation to hypoglycaemic symptoms with the technique of monitoring blood glucose concentrations at home. 
TABLE I - Characteristics of 12 subjects with symptoms of functional hypoglycaemia and 12 matched healthy control subjects. Values are means (SD) unless stated otherwise

\begin{tabular}{|c|c|c|c|c|}
\hline & \multicolumn{2}{|c|}{ Patients with functional hypoglycaemia } & \multirow[b]{2}{*}{ Controls } & \multirow[b]{2}{*}{ p Valuest } \\
\hline & $\begin{array}{c}\text { Symptoms } \\
(\mathrm{n}=6)^{\star}\end{array}$ & $\begin{array}{c}\text { No symptoms } \\
(n=6)^{\star}\end{array}$ & & \\
\hline $\operatorname{Sex}(M, F)$ & 2,4 & 2,4 & 3,9 & $1 \cdot 0 / 1 \cdot 0$ \\
\hline Age (years) & $47(15)$ & $43(9)$ & $42(12)$ & $0 \cdot 6 / 0 \cdot 4$ \\
\hline Body mass index $\left(\mathrm{kg} / \mathrm{m}^{2}\right)$ & $22 \cdot 8(3 \cdot 6)$ & $22 \cdot 5(1 \cdot 2)$ & $23 \cdot 1(2 \cdot 8)$ & $0 \cdot 7 / 0 \cdot 9$ \\
\hline
\end{tabular}

*Hypoglycaemic symptoms during study

tAll patients $v$ controls/symptoms $v$ controls.

TABLE II - Results of analysis of variance of six daily blood glucose values from four consecutive days in 12 subjects with symptoms of functional hypoglycaemia and 12 control subjects. Values are means (SD)

\begin{tabular}{lcccc}
\hline \multicolumn{4}{c}{ Patients with functional hypoglycaemia } \\
\cline { 2 - 3 } & $\begin{array}{c}\text { Symptoms } \\
(\mathrm{n}=6)^{\star}\end{array}$ & $\begin{array}{c}\text { No symptoms } \\
(\mathrm{n}=6)^{\star}\end{array}$ & Controls & p Values $\dagger$ \\
\hline Blood glucose (mmol/1) & $5 \cdot 0(0 \cdot 2)$ & $5 \cdot 1(0 \cdot 5)$ & $5 \cdot 0(0 \cdot 3)$ & $0 \cdot 5 / 1 \cdot 0$ \\
Within subject variation & $0 \cdot 55(0 \cdot 24)$ & $0 \cdot 77(0 \cdot 56)$ & $0 \cdot 50(0 \cdot 26)$ & $0 \cdot 3 / 0 \cdot 7$ \\
Coefficient of variation & $14 \cdot 2(3 \cdot 4)$ & $15 \cdot 6(4 \cdot 9)$ & $13 \cdot 4(2 \cdot 9)$ & $0 \cdot 8 / 0 \cdot 7$ \\
Glycated haemoglobin (\%) & $5 \cdot 4(0 \cdot 8)$ & $5 \cdot 7(0 \cdot 3)$ & $5 \cdot 2(0 \cdot 4)$ & $0 \cdot 1 / 0 \cdot 5$ \\
& & & &
\end{tabular}

^Hypoglycaemic symptoms during study.

tAll patients $v$ controls/symptoms $v$ controls.

TABLE III - Mean composition (percentage of total energy intake) of food and drinks ingested during four days of blood glucose monitoring in 12 subjects with functional hypoglycaemia and 12 control subjects

\begin{tabular}{lcc}
\hline & $\begin{array}{c}\text { Patients with } \\
\text { functional } \\
\text { hypoglycaemia }\end{array}$ \\
\hline Fibre & 4 & 4 \\
Sugars & 14 & 14 \\
Starch & 23 & 24 \\
Protein & 14 & 14 \\
Fat & 42 & 40 \\
Alcohol & 3 & 4 \\
\hline
\end{tabular}

${ }^{\star}$ Mean intake $8869 \mathrm{~kJ} /$ day †Mean intake $9672 \mathrm{~kJ} / \mathrm{day}$.

\section{Subjects and methods}

Over three and a half years 21 subjects with suspected hypoglycaemia were referred to this hospital for evaluation. All had normal fasting insulin, C peptide, and proinsulin concentrations and no circulating insulin antibodies. Twelve subjects with persistent symptoms agreed to take part in the monitoring of blood glucose concentrations at home over four consecutive days, as did a control group matched for sex, age, and weight. The control subjects were healthy volunteers without hypoglycaemic symptoms who were recruited from the medical staff. All were instructed to draw six daily blood samples in fixed relation to meals: just before breakfast; two hours after breakfast; just before lunch; three hours after lunch or before eating a snack; just before dinner; and at bedtime. Extra samples were taken at the onset of symptoms. During the four days of monitoring the type and amount of all consumed food and drinks were recorded.

Samples were taken by the finger prick method directly into a glass tube $(10 \mu \mathrm{l})$. The tubes were immediately put into small plastic containers and sent by post daily to our laboratory for analysis (dehydrogenase method, Gluc-DH, Merck). Glycated haemoglobin concentration was measured by high performance liquid chromatography (Bio-Rad DIAMAT, Richmond, California); the normal range is $4 \cdot 3-6 \cdot 2 \%$.

One way analysis of variance and Student's $t$ tests for unpaired differences were used in the comparison of groups. The level of significance was taken to be $5 \%$.

\section{Results}

Nineteen out of 21 subjects admitted consecutively had persistent hypoglycaemic symptoms after one to three years of observation.

Table I shows the characteristics of the subjects who entered the case-control study. The reported symptoms of the 12 patients were difficulty in thinking (10 patients); fatigue (10); sweating (eight); shakiness (eight); dizziness (six); headache (six); hunger (six); blurred vision (five); and palpitations (three). They had experienced a mean of two weekly episodes (range $0 \cdot 5-20$ ) for two to 50 years lasting a mean of 10 minutes (range 2-30). A clear relation to meals was present in nine subjects and additional fasting episodes occurred in six. Symptoms weakened or disappeared after eating in all subjects.

Six patients experienced nine episodes with their usual symptoms during the four days of the study: one patient had three episodes, one two episodes, and four one episode. Blood glucose concentrations ranged from $3.7 \mathrm{mmol} / 1$ to $7.5 \mathrm{mmol} / \mathrm{l}$ during these episodes. Apart from hunger, which was reported by all six subjects, the pattern of symptoms was comparable with that in the whole group.

The mean changes in blood glucose concentration (figure) and mean blood glucose values at each time point were not significantly different from those in the control group, both for all patients and for the six patients reporting symptoms. No blood glucose values

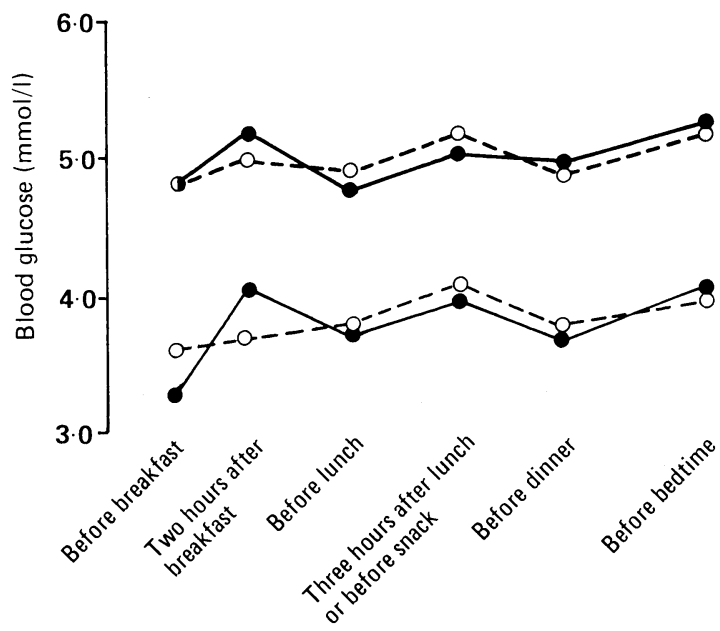

Mean blood glucose values on four consecutive days (top) and lowest measured values (bottom) in 12 subjects with functional hypoglycaemia $(-\mathrm{O})$ and 12 matched control subjects $\left(\mathrm{O}_{-} \mathrm{O}\right)$

were below $3.3 \mathrm{mmol} / \mathrm{l}$ in any subject. Furthermore, the overall mean blood glucose concentration, the within subject variation in blood glucose values, and the glycated haemoglobin values showed no significant differences between groups (table II).

The patients as a whole consumed an average of 8869 (SD 2475) kJ/day, those with symptoms during the study 9766 (3036) kJ/day, and the control subjects $9672(1679) \mathrm{kJ} /$ day $(p=0 \cdot 9)$. No significant differences in the composition of the ingested food and drinks were observed (table III).

\section{Discussion}

In our controlled study of subjects with functional hypoglycaemia we did not find chemical hypoglycaemia during everyday life or in relation to symptoms. This suggests that Whipple's triad of the clinical features of insulin producing tumours (spontaneous hypoglycaemia $(<2.8 \mathrm{mmol} / \mathrm{l})$, central nervous or vascular system symptoms, and relief of symptoms by oral glucose) is not fulfilled in functional hypoglycaemia. Larger controlled studies and systematic giucose monitoring at the onset of symptoms should, however, be performed to settle whether blood glucose monitoring can delineate a subpopulation of patients with true hyoglycaemia among subjects with functional hypoglycaemia. The widely used oral glucose tolerance test in the diagnosis of this condition is considered inappropriate for this purpose. ${ }^{56810}$

A mixed meal has been suggested as a possible diagnostic test but has generally failed to show any differences in blood glucose concentrations between normal subjects and those with symptoms or any differences in hormone concentrations. ${ }^{4112}$ An association between the lowest blood glucose concentration and symptoms has been shown only in a small group of seven subjects who were given sucrose cakes. ${ }^{13}$

Thus the characteristic symptoms of hypoglycaemia and their disappearance after eating are still our 
only criteria. The clear persistence of the symptoms suggests that functional hypoglycaemia is a clinical condition. The general failure to show chemical hypoglycaemia, however, questions the use of the term functional hypoglycaemia and suggests a different explanation for the phenomenon. The glycaemic threshold for onset of hypoglycaemic symptoms and release of counterregulatory hormones might be higher than in normal subjects. Further studies should test this hypothesis.

In conclusion, hypoglycaemic symptoms seem to be persistent in subjects with functional hypoglycaemia but are not related to chemical hypoglycaemia. This suggests the existence of a clinical condition but questions whether the commonly used term for this condition is appropriate.

1 Yager J, Young RT. Non-hypoglycemia is an epidemic condition. $N$ kingl $\mathcal{f}$ Med 1974;291:907-8.

2 Betteridge DJ. Reactive hypoglycaemia. Br.Med 7 1987;295:286-7.
Gastineau CF. Is reactive hypoglycemia a clinical entity? Mayo C/in I'rou 1983:58:545-9.

Hogan MJ, Service FJ, Sharbrough RW, Gerich JE Oral glucose tolerance est compared with a mixed meal in the diagnosis of reactive hypoglycemia. Mavo Clin Proc 1983:58:191-6.

5 American Diabetes Association. Statement on hypoglycemia. Diabetes (iar 1982:5:72-3.

6 Marks V. Functional hypoglycemia: fact or fancy? In: Andreani D, ed. Hypoglycemia Serono Sumposia 1986:38:1-17.

Bernstein RK. Meaningful screening test for reactive hypoglecemia. Diabetes Care 1987:10:792-3.

8 Lev-Ran $A$, Anderson RW. The diagnosis of postprandial hepoglvcemia. Dlabetes 1981;30:996-9.

9 Jung Y, Khurana RC, Corredor DG, et al. Reactive hypoglycemia in women Diabetes 1971;20:428-34.

10 Lefebvre P'J, Andreani D, Marks V, Creutzfeldt W. Statement on "post prandial" or "reactive" hypoglycaemia. Diabetologia 1988;31:68-9.

11 Charles MA, Hofeldt FD, Shackelford A, et al. Comparison of oral glucose tolerance tests and mixed meals in patients with apparent idiopathic postabsorptive hypoglvcemia. Diabetes 1981:30:465-70.

12 Buss RW, Kansal PC, Roddam RF, Pino J, Boshell BR. Mixed meal tolerance test and reactive hypoglycemia. Horm Metabol Res 1982;14:281-3.

13 Crapo PA, Scarlett JA, Kolterman OG, Sanders LR, Hofeldt FD, Olefsky JM. The effects of oral fructose, sucrose, and glucose in subjects with reactive hypoglycemia. Diabetes Care 1982;5:512-7.

Accepted 30 September 1989)

\title{
Single dose cefotaxime plus metronidazole versus three dose cefuroxime plus metronidazole as prophylaxis against wound infection in colorectal surgery: multicentre prospective randomised study
}

\author{
D C Rowe-Jones, A L G Peel, R D Kingston, J F L Shaw, C Teasdale, D S Cole
}

Abstract

Objective-To establish whether a single preoperative dose of cefotaxime plus metronidazole was as effective as a standard three dose regimen of cefuroxime plus metronidazole in preventing wound infection after colorectal surgery.

Design-Prospective randomised allocation to one of two prophylactic antibiotic regimens in a parallel group trial. Group sequential analyses of each 250 patients were performed.

Setting-14 District general and teaching hospitals.

Patients-1018 Adults having colorectal operations were randomised, of whom 943 were evaluated. Demographic features, conditions requiring surgery, and operative procedures were similar in the two groups. Most patients had surgery for carcinoma of the colon or rectum.

Interventions-Group 1 received cefotaxime $1 \mathrm{~g}$ intravenously plus metronidazole $500 \mathrm{mg}$ intravenously preoperatively. Group 2 received cefuroxime $1.5 \mathrm{~g}$ intravenously plus metronidazole $500 \mathrm{mg}$ intravenously preoperatively, followed by cefuroxime $750 \mathrm{mg}$ intravenously plus metronidazole $500 \mathrm{mg}$ intravenously eight hours and 16 hours postoperatively.

Main outcome measures-Development of surgical wound infection (as evidenced by the presence of pus), death, or discharge from hospital.

Results - Wound condition was scored on a five point scale on alternate days until discharge or for up to 20 days postoperatively. Wound infection rates were: group $1,32 / 453(7 \cdot 1 \% ; 95 \%$ confidence interval $4.7 \%$ to $9.4 \%)$; group $2,33 / 454(7 \cdot 3 \%$; $95 \%$ confidence interval $4.9 \%$ to $9 \cdot 6 \%$ ). Death rates (group 1: $26 / 470(5 \cdot 5 \%)$; group 2: $31 / 471(6 \cdot 6 \%)$ ), the incidence of postoperative complications, the median duration of hospital stay (12 days), and antibiotic tolerance were all similar in the two groups. Pooled data from groups 1 and 2 showed that wound infections were more frequent when minor faecal contamination had occurred at operation and when the duration of operation exceeded 90 minutes ( $>90 \mathrm{~min} 11.2 \%$ of cases; $<90 \mathrm{~min} 4.8 \%$ ) and were associated with an extended hospital stay.

Conclusions-A single preoperative dose of cefotaxime plus metronidazole is as efficacious as a three dose regimen of cefuroxime plus metronidazole in preventing wound infection after colorectal surgery and has practical advantages in eliminating the need for postoperative antibiotics.

\section{Introduction}

The use of antibiotics for prophylaxis against wound infection is well established in patients having operations on the gastrointestinal tract, particularly the large bowel, where the risk of infection from faecal micro-organisms is high. ${ }^{2}$ Despite acceptance of antibiotic prophylaxis in principle there is wide variation in the composition and duration of the antibiotic regimens employed. ${ }^{34}$ The ideal prophylactic regimen for large bowel surgery would exemplify activity against both aerobic and anaerobic bacteria with a consequent low incidence of wound infection, safety from unwanted drug effects, convenience of delivery, and low cost. A single preoperative dose of prophylactic antibiotics shown to be of equal efficacy to a commonly used multiple dose regimen would satisfy these criteria. Though single dose regimens are established for "clean" procedures such as operations on the biliary and upper gastrointestinal tracts, convincing and statistically sound evidence for efficacy is lacking in procedures such as colorectal surgery, which have a potentially much greater degree of contamination.

Several studies have investigated the role of single dose preoperative systemic antibiotics alone or compared with multiple dose regimens in patients having colorectal surgical procedures. The single dose regimens tested have included a ureidopenicillin $\left(\operatorname{mezlocillin}^{6}\right)$, cephalosporins (cefuroxime, ${ }^{7-9}$ cefo- 